\title{
LA ORDENACION DEL TERRITORIO Y EL NUEVO MARCO INSTITUCIONAL
}

$71: 342.14(46)$

por

Ramón Martín Mateo

SUMARIO: I. LA PLANIFICACION REGIONAL.-II. ANTECEDENTES.-III. LA ORDENACION DEL TERRITORIO Y LA NUEVA LEGISLACION URBANISTICA.-IV. LOS PLANES DIRECTORES TERRITORIALES DE COORDINACION.-V. COORDINACION, EFICACIA Y SISTEMA DE AUTONOMIAS.

\section{LA PLANIFICACION REGIONAL}

Se abre brecha en este ciclo con un tema que no es exclusivamente jurídico, ligeramente alejado de la temática positivista del Derecho y más propio de lo que pudiera denominarse en otros medios ingeniería social.

Los Planes Directores Territoriales de Coordinación, en definitiva, son reconducibles a una problemática más amplia, que es la que técnicamente se califica, sobre todo a medida que ha ido recibiéndose de los medios americanos, como planificación regional, aunque en la rúbrica regional tengan otras connotaciones no siempre trasladables al plano de la ordenación del territorio, sino también, como es sabido, remita preocupaciones de índole cultural, político, etc. 
Los planes que ahora analizamos constituyen instrumentos adecuados para institucionalizar, a través de su concreción, aspiraciones a una mejor distribución de usos dentro de un determinado territorio. Por ello nos convendría antes hacer un ligero énfasis en lo que consideramos el desiderátum de la planificación espacial.

En primer lugar, la planificación regional, a escala supramunicipal, pretende ser una síntesis a largo plazo de la planificación física y de la planificación económica. Esto es ni más ni menos lo que viene llamándose ordenación del territorio, en sentido estricto, porque en un sentido amplio se entiende por tal toda operación que tiene como misión una mayor racionalización del uso del espacio. Ordenación del territorio en el sentido técnico y preciso aquí asumido, es precisamente un conjunto de decisiones sobre utilización óptima de un territorio a nivel de grandes lineamientos con un horizonte temporal de medio y largo plazo y de forma tal que el espacio en cuestión constituye una plataforma adecuada para una máxima potenciación de los intereses socioeconómicos de las comunidades que le habitan.

Es, pues, insisto, una síntesis física y económica de un proceso de racionalización territorial de conductas sociales. La planificación regional y la ordenación del territorio en cuanto técnica a su servicio suponen la desagregación de pronunciamientos de relevancia espacial que, partiendo de decisiones de amplio espectro, principales y genéricas, se desagregan a través de un escalonamiento progresivo que incluye opciones más matizadas y comprometidas sobre usos específicos de determinadas porciones del espacio.

Este tipo de planificación pretende una adecuación de los espacios sociales y de los espacios económicos, y de éstos con los administrativos; de aquí la necesidad de su institucionalización. De nada vale, como, por ejemplo, sucede en determinados países que tienen una pauta pionera y avanzada en estas técnicas de planificación, como los anglosajones, sobre todo Estados Unidos, avanzar con gran sofisticación teórica en estas modalidades, si no existen elementos institucionales que permitan que las decisiones de los políticos adopten, como consecuencia de las propuestas de los expertos, puedan ser transmitidas a la realidad, transformando la vida social mediante la organización necesaria. De aquí que se necesite un esfuerzo conducido de la mano del Derecho, que innove el ordenamiento jurídico y reconduzca las conductas espontáneas y autónomas a las 
actuaciones mejor asumibles sobre un espacio concreto en función de las necesidades colectivas de todos los que le habitan.

Estas operaciones serían pura tecnocracia o mera especulación de laboratorio si en su implantación, en su trasunto a escala de modulaciones políticas, no se viesen respaldadas y animadas por las propias voluntades de los ciudadanos a que van dirigidas; también aquí aparecen, como es inevitable, una de las constantes generales de la ordenación contemporánea, cual es la inserción de la democracia en el proceso de adopción de decisiones, y la participación efectiva de los afectados.

La planificación regional, a la que, insisto, se reconduce a la postre la ordenación del territorio implicará, si queremos que sea eficaz, la conjunción de una serie de esfuerzos que desde diversos ángulos y escalas van a hacer posible que el tejido físico del territorio incorpore a aquellos usos considerados óptimos, incluyendo el equipamiento, la infraestructura y los elementos complementarios de apoyo, a los usos principales. Ello supondrá un esfuerzo de coordinación sectorial de diversas administraciones y organizaciones que, de una forma $u$ otra, deben concurrir con sus competencias respectivas, sean éstas en el ramo de los viales, del suministro de servicios, etc., a la operación final de racionalización del territorio, suministrando cauces adecuados para la efectividad de la planificación.

Es sabido que el gran riesgo de la planificación es precisamente su inoperancia, el que a escalas modestas y acotadas, como puede ser un plan parcial, las posibilidades de ejecución son en muchos casos hipotéticas, porque no se cuenta con unos dispositivos adecuados, con organizaciones idóneas, que asuman estas responsabilidades y las lleven a efecto. En el campo de la ordenación territorial, de la macroplanificación, las dificultades se agigantan, y es frecuente que estudios magníficos, pormenorizando indagaciones, valiosas prospectivas, terminen estérilmente en los olvidados estantes de algún archivo público porque no había detrás una infraestructura organizatoria y ejecutiva adecuada para llevar a efecto la planificación propuesta.

Felizmente, como más adelante insistiremos, la nueva configuración de la distribución interior del Estado español nos puede facilitar ahora este tipo de apoyos, permitiéndonos mirar con mayor optimismo y esperanza las posibles virtualidades y bondades a estas acciones. 
La planificación regional implica asignar protagonismo y dar relevancia a un determinado espacio intermedio. Tradicionalmente, el urbanismo se venía apoyando en unos espacios muy concretos coincidentes con las ciudades, y a lo más, un poco más allá, con las Comarcas. Modernamente, contemporáneamente, se han percatado casi todas las Administraciones de la necesidad de utilizar una estrategia que incluya al menos dos niveles, uno más amplio, más general, de vocación directiva, y otro en el que se asientan decisiones más pormenorizadas y concretas. Este tipo de comprensión ha tenido su trasunto en instrumentos planificadores de múltiples Naciones, tal sucede en los países occidentales, por ejemplo, con los planes directivos italianos, con los esquemas directores franceses y los planes de estructura ingleses. La revisión de la Ley del Suelo española incorpora también estas técnicas, que no constituyen una innovación o un puro arbitrismo legislativo, sino la recepción de lo que ya existe en casi toda Europa, que es tardíamente incorporado a nuestro ordenamiento.

Hay que decir, sin embargo, que este tipo de planes donde mejor han funcionado, como es lógico por lo demás, es en aquellos países donde la planificación en su conjunto, tanto la económica como la espacial, disponen de palancas energéticas. Es, por tanto, en las Naciones socialistas donde han hecho, que yo sepa, una auténtica ordenación del territorio con planes que se han llevado a efecto tal como habían sido concebidos y a escalas bastante amplias, destacándose en la literatura especializada el caso de Polonia.

Pero creo que dentro de los regímenes democráticos occidentales, aunque con mayores dificultades, felizmente desde otra perspectiva, existen también posibilidades de orientar la economía al hilo de acciones espaciales.

Los Planes Directores Territoriales de Coordinación españoles, expresión ésta poco afortunada, más bien una definición que propiamente una rúbrica, responden, entre otros objetivos, a este conocido propósito de suministrar instrumentos para la ordenación regional y el desarrollo regional. Son planes de carácter supramunicipal, en principio, que tienen unos modestos precedentes en algunos intentos de la legislación anterior. La Ley del Suelo, en su primera versión, recogía ya, por ejemplo, a la máxima escala piramidal los planes nacionales de urbanismo; sabido es que tales planes nunca se han llevado a efecto, ni siquiera se ha hecho ningún intento serio en este sentido, lo que no es excepcional para nuestra 
Nación. La legislación del suelo también preveía planes provinciales, que tampoco tuvieron vigencia, aunque ha habido algunos intentos en la propia Asturias, me parece que simplemente a nivel de recogida de información y análisis, y en alguna otra Provincia, como Guipúzcoa, donde por los años sesenta el equipo de Doxiades realizó una primera versión. También en Barcelona se avanzó una cierta planificación provincial, pero en ningún caso se llegó nunca a su institucionalización, porque no había tampoco elementos capaces de asumir la gerencia del plan ni posibilidades de establecer una disciplina del urbanismo a esta escala. Bajo el régimen de la antigua Ley del Suelo no hubo más que aproximaciones de carácter técnico, muy meritorias algunas, pero sin resultado práctico.

\section{ANTECEDENTES}

La Ley del Suelo también preveía la existencia de planes comarcales; algunos de éstos, muy pocos, se adoptaron efectivamente o se proyectaron, pero tampoco hubo avances significativos, pese a que aquí sí se podía disponer de elementos institucionales más eficaces, como son las mancomunidades de urbanismo, que de hecho se crearon aisladamente en ciertos Municipios como en Sabadell y Tarrasa, agrupando a varios Municipios para gerenciar un plan común. Sin embargo, estas experiencias han sido parciales, episódicas, y no se han llevado a efecto con resultado plenamente satisfactorio. Ha habido después otros intentos, como los programas de acción urbanística, de ambiciones más amplias, pero tampoco han pasado de ser un puro planteamiento sobre el papel.

Esto en cuanto a la ordenación exclusivamente espacial. Con referencia a la espacialización de la actividad económica, deben mencionarse las técnicas ya superadas de los polos de desarrollo, aunque utilizadas, de forma apriorística, sin suficiente análisis ni valoración del impacto sobre los espacios de los territorios aledaños. Deben mencionarse también los planes regionales más o menos enfáticos para ciertas zonas, como Levante y Canarias, y luego las denominadas grandes áreas de desarrollo industrial; pero tampoco esto, insisto, ha tenido una mayor virtualidad. 


\section{LA ORDENACION DEL TERRITORIO Y LA NUEVA LEGISLACION URBANISTICA}

Con ocasión de la revisión de la Ley del Suelo, estas técnicas se consagran por el legislador con generalidad y rigor, aunque hay que decir que siguen prácticamente inéditas en cuanto a resultados efectivos, puesto que creo que sólo han sido constituidos tres equipos para estudiar planes de este tipo y no se conocen aún los resultados, aunque sospecho que no se ha progresado mucho y que quizá se ha incidido en el conocido error de agotar ad libitum la información, aun sin saber muy bien para qué. Los PDTC se inscriben en el conjunto de sistemas desagregados y escalonados que plantea la Ley del Suelo, y que incluye un plan nacional de ordenación del territorio, que no será normalmente un plan en el sentido que estamos acostumbrados a contemplar, sino, en el supuesto de que se lleve a efecto, sería un documento que realizaría grandes opciones, incluyendo alternativas muy amplias y pronunciamientos, por ejemplo en materia de infraestructuras, muy genéricos. El plan establecería la gran infraestructura en materia de autopistas, de aeropuertos, de puertos de interés general, de gaseoductos, de oleoductos, etc.; esto es lo más que podría hacer $\mathrm{o}$, a lo más, podría pronunciarse sobre la vocación agrícola, turística o industrial de determinadas áreas. Este plan estaría bastante alejado de lo que consideramos plan territorial. Difícilmente tendría aspectos suficientemente normativos como para deducir un trasunto de cierta imperatividad. Por lo demás, el legislador, quizá tardíamente, puesto que le alude en las disposiciones transitorias, se ha dado cuenta de las dificultades de esta empresa y ha privado al sistema planificador general de la obligación inexcusable de pasar por este plan; es decir, los PDTC no necesitan de la apoyatura previa en el plan nacional, sin perjuicio de que algún día éste se apruebe, en cuyo caso se plantearía la incógnita de cómo afectaría a aquellos planes, si deberían ser revisados, actualizados o transformados de acuerdo con las previsiones del plan nacional y si a su vez los planes generales municipales que se apoyan en los directores iban a ser también objeto de revisión, con lo que el plan podría ser un elemento de disloque, de distorsiones de todo el aparato planificador. 


\section{LOS PLANES DIRECTORES TERRITORIALES DE COORDINACION}

El plan nacional sería, pues, simplemente un intento de armonización de acciones de gran escala, suministrando pautas generales orientativas, siendo en los PDTC donde aparecerían elementos directivos con auténtica virtualidad propia. El artículo $8 .^{\circ}$ de la Ley del Suelo nos dice, como lo ha hecho ya anticipadamente la exposición de motivos, que los Planes Directores Territoriales de Coordinación establecerán, de conformidad con los principios del Plan Nacional de Ordenación, en el supuesto que exista, de la planificación económica y social, y de las exigencias del desarrollo regional, las directrices para la ordenación del territorio, el marco físico en que han de desarrollarse las previsiones del plan, y el modelo territorial en que han de coordinarse los planes y normas a que afecte.

El primer escollo que aparece aquí es la remisión a la planificación económica. Como es sabido, este tipo de planificación ha tenido a escala de los países occidentales una cierta crisis generalizada, aunque todavía se mantiene vigente en algunas Naciones, como Francia, con alguna efectividad, al menos la de suponer una reflexión en común de la Administración y un nexo con la actividad privada, pero entre nosotros hace tiempo que estas técnicas ni siquiera formalmente se materializan, pese a las referencias constitucionales. Incluso se han desmantelado los instrumentos, personales y materiales, al servicio de la planificación y no se ha vuelto a aludir, más que críticamente, a los planes de desarrollo de las décadas del optimismo. En estos momentos, pues, no hay ningún barrunto de que vaya a haber nuevamente planificación ni siquiera con los tímidos objetivos indicativos que tenía en la etapa anterior.

Va a ser muy difícil que los PDTC se apoyen en planes de desarrollo de escala estatal, tarea ésta, además, problemática, dados los instrumentos tan escasamente contundentes de que se dispone. Pero a estas escalas, como las propiamente regionales, sí parece que pueda ser relativamente viable con la nueva organización de las autonomías, lo que trataremos rápidamente al final. Las Regiones podrán repensar así su propio futuro y reflexionar sobre su progreso, dentro de los cauces que les correspondan, estableciendo horizontes de desarrollo y metas económicas apoyadas en cierta estrategia económica a medio plazo que pueda venir soportada por una determinada organización espacial. 
Saliendo, pues, de ámbitos demasiado ambiciosos y superando los planteamientos que implican la programación económica a nivel estatal, podemos pasar a escalas más tangibles e inmediatas, donde las presunciones pueden ser posiblemente más realistas y donde cabe intentar encauzar el desarrollo de la Región mediante la conjunción de la planificación económica y la física. Hay aquí, no obstante, una serie de incógnitas que se nos tiene que desvelar, como sucede con los mecanismos institucionales, que han sido contemplados por la Constitución, pero que todavía no han entrado, ni de lejos, en funcionamiento: me refiero a los fondos para el trasvase de recursos de unas Regiones a otras, o al sistema de ingresos propiamente de las Comunidades autónomas, de las subdemarcaciones territoriales interiores del Estado. Pero hay todavía otras incógnitas más importantes, que harán cavilar notablemente a los planificadores regionales, como son los posibles cursos de la coyuntura y el comportamiento de variables de escala internacional.

Los PDTC que estamos contemplando constituyen, según han puesto de relieve destacados especialistas en materia de Derecho urbanístico, como los profesores GARCía DE ENTERRfa y PAREJo en su reciente monografía de Derecho urbanístico, el acierto más destacable de la reforma de la legislación del suelo, aclimatando entre nosotros experiencias válidamente contrastadas en otros países, poniendo a disposición de los políticos y de los técnicos instrumentos útiles para una mayor racionalización del uso del espacio y el mejor progreso de su entorno económico.

Se trata de planes fundamentalmente coordinadores, que tienen, por tanto, la ventaja de una cierta flexibilidad para el desarrollo espacial y económico. Su indeterminación espacial no apriorística, ha obviado caer en la tentación homogeneizadora propia del cartesianismo continental en el que nosotros estamos insertos culturalmente. La legislación no lo ha hecho así, sino que ha permitido que el modelo se ajuste a medida de las necesidades de los distintos espacios; esto, pues, es un dato positivo que debemos tener en cuenta a la hora de intentar su manejo.

Se trata, no obstante, de auténticos planes y no de meras especulaciones o simples proyecciones o reflexiones de futuro. Son planes, puesto que podemos predicar de ellos el carácter directivo, vinculante; es decir, la aprobación de estos planes va a sujetar a sus dictados conductas públicas y privadas, influyendo sobre los planes 
generales municipales, los planes parciales y los programas de actuación urbanística. Son planes, pues, imperativos, normativos y obligatorios tanto para la Administración como para los administrados.

Los Ayuntamientos, una vez que se aprueben los PDTC, vendrán obligados a acomodar a éstos los planes ya aprobados, revisándolos. Su directa e inmediata vinculación, una vez que se adopten, afectará a futuros usos, aunque claro está que por su propia naturaleza no pormenorizarán sobre temas como volúmenes o tipos de industria, pero si, en grandes determinaciones, pueden establecer, por ejemplo, que una zona será fundamentalmente agraria, y a partir de ese momento, y aunque no haya planes municipales que los desarrollen, no se podrán establecer usos contrarios a estas previsiones globales, pero ya definidas por estos planes.

Los PDTC pretenden servir a la ordenación integral del territorio, aunque qué territorio sea es algo sobre lo que el propio plan habrá de pronunciarse. Estimo que su vocación natural es servir de base espacial al desarrollo regional, entendiendo como desarrollo de las áreas que hoy integran el Estado español, con sustantividad ya alcanzada o en trance de adquirir su institucionalización. Pero pueden valer también para el regimiento de Comarcas, porque esto es una de sus posibilidades espaciales más singulares y, desde luego, deberán tener, a mi juicio, una importancia extraordinaria en la organización de las áreas metropolitanas. Creo sinceramente que, viviendo la experiencia de estas comunidades, se constata que hoy no es posible organizar espacialmente un área metropolitana sobre la base de planes generales, por ejemplo el Plan del Gran Bilbao, en revisión hace casi diez años, ha sido incapaz de encontrar continuidad. Las áreas metropolitanas exigen forzosamente unos planes directivos, genéricos, que luego, ya por sectores, por Municipios o por áreas más circunscritas, serán desarrollados con mayor intensidad.

Estos son, pues, los posibles ámbitos espaciales, pero, insistimos, será el propio plan, y ahí está la originalidad de la técnica, el que va a determinar su espacio. Para ello habrá de detectarse previamente cuál sea el sistema sociourbano o socioeconómico que conviene o que interesa disciplinar, orientar y encauzar. Una vez precisada la comunidad o supercomunidad en cuestión, se ajustará el esquema del plan y el modelo territorial y económico que postula.

La Ley asigna al plan, entre otras funciones, la determinación 
de una zonificación genérica, la fijación de áreas de interés público que pueden ser de interés militar o de otro tipo, por ejemplo, las contempladas en la Ley de Costas o en la Ley de Defensa de 1979. También prevé el establecimiento de zonas de protección, ambientales, ecologistas, etc., y el señalamiento de una serie de programas que van a llevar a efecto sus previsiones.

\section{COORDINACION, EFICACIA Y SISTEMA DE AUTONOMIAS}

La principal dificultad de una planificación del tipo que nos ocupa, es precisamente su capacidad efectiva para disciplinar a todas las múltiples unidades administrativas que de una forma $u$ otra deben cooperar a sus resultados; de aquí que la Ley del Suelo, ingenuamente a mi juicio, quisiera solventar este escollo mediante la integración en el proceso de adopción del plan de numerosas Administraciones y entidades con la esperanza quizá de su compromiso para el proceso de ejecución.

La Ley del Suelo y el Reglamento de Planeamiento establecen un proceso complejo y minucioso para la formación de estos planes, dando entrada a los Ministerios, Diputaciones, Municipios, etcétera, que tengan interés en el plan, para que se identifiquen con sus objetivos y se comprometan para las operaciones que posteriormente deben llevarse a efecto. Esto es, no obstante, problemático; ya sabemos que una de las dificultades máximas de las organizaciones modernas son los temas de la coordinación y de la operatividad.

El Derecho administrativo tiene dispositivos y respuestas eficaces y contundentes ante determinadas acciones administrativas que violan el ordenamiento y que perjudican legítimamente a los particulares; pero las medidas de disciplina de la Administración moderna fallan en cuanto a la imposición de acciones concretas, y a la exigencia de respuestas eficaces a problemas planteados. También es difícil conseguir una acción coordinada, mancomunada, conjunta, de distintas entidades administrativas proclives, como sabemos, a su mutuo desconocimiento, al aislamiento, a la creación de múltiples reinos de Taifas.

Esto afecta directamente a los PDTC, aunque se prevean mecanismos de seguimiento y organizaciones responsables de su puesta en efectividad. Cómo pueda ser esta organización y cuál sea el elemento aglutinador y gerencial del proceso es algo que queda un tanto en el aire, si bien las nuevas organizaciones de carácter 
regional pueden segregar perfectamente una unidad encargada de vigilancia, de la puesta en acción de los dispositivos específicos para que, por ejemplo, donde se ha previsto simplemente una infraestructura ésta se cree, y donde se ha determinado un cambio se produzca.

Estas consideraciones nos reconducen a un hecho nuevo, que se ha producido después de que el legislador del suelo terminase su tarea: me refiero al tema de las autonomías y de las preautonomías y a las nuevas unidades de Administración Territorial.

El proceso de planificación que inicialmente se establecía, partía del Ministerio de la Vivienda-hoy Ministerio de Obras Públicas y Urbanismo-y terminaba en el Consejo de Ministros. Los planes se delineaban fundamentalmente como planes estatales, y sólo excepcionalmente se preveía que las Diputaciones pudiesen iniciarlos. Existía, pues, un trasunto central muy intenso, hasta cierto punto lógico, aunque no fuese de recibo la ausencia del protagonismo más inmediato de las comunidades locales. Pero es cierto que los que iban a intervenir en la dotación del espacio con los elementos previstos por el plan iban a ser normalmente Administraciones, unidades, Departamentos y Ministerios vinculados con la Administración central. De aquí que pareciese natural que la sanción definitiva de este plan terminase en el Consejo de Ministros, aunque con ello se incidía a la par en una ingenuidad reiterada en nuestro ordenamiento: la creencia de que un plan sancionado por el Consejo de Ministros va a ser acatado por todos los Ministerios. La práctica nos dice, sin embargo, que esto no es forzosamente así.

Pero ahora sucede que entre las competencias que se transmiten en exclusiva y a los nuevos entes autonómicos, e incluso a los preautonómicos, está la ordenación del territorio y el urbanismo in totum, lo que quiere decir que la aprobación y la formación de los PDTC quedará dentro del ámbito del propio órgano autonómico.

Esto es una ventaja indudable en cuanto a flexibilidad, agilidad e identificación de la problemática; pero ofrece inconvenientes notables, y es que no todo lo que el plan va a prever está en la mano de los órganos regionales correspondientes. Tal es el caso de las grandes infraestructuras; por ejemplo, cualquier plan tiene que afrontar un tema tan capital como la conservación, mejora, potenciación o ampliación de la red de transportes, de ferrocarriles, y posiblemente habrá de afrontar un abastecimiento de aguas a escala suprarregional, y si la Administración central no interviniese 
quedará desvinculada del plan. Pero de alguna forma habrá que hacer estos enganches, si se quiere que los planes sean realistas. Es normal que el protagonismo descanse sobre las instancias locales; pero si las centrales se inhiben va a ser muy difícil que estos planes prosperen. Esta es una incógnita que, sin duda, por la novedad de los planteamientos políticos ulteriores a la Ley del Suelo, habrá de despejarse; a lo mejor no es necesario nueva normación, sino que bastará llegar a un sistema de acuerdos no formalizado previamente.

Expuestas en sus grandes líneas las características de la planificación que constituye el objeto de la presente exposición, cabe añadir que a las positivas ventajas que comporta para una Región el hecho de haber sancionado un PDTC, debe sumarse lo que supondrán además en cuanto a inyección de optimismo, al refuerzo del deseo de autosuperación en cuanto apuesta de futuro. Una operación animosa que muchas de las Regiones y Nacionalidades españolas seguramente pretenderán acometer, porque ello, de forma, supone la ratificación de su voluntad colectiva y no necesariamente un mero brindis al sol.

Ahora bien, existen factores que tenemos que tener en cuenta sobre la modestia con que los planificadores deben operar. Hoy en día será necesario hacer un esfuerzo de futurología, arriesgado, sobre la incidencia de factores que están fuera del alcance del planificador. En estos momentos flota una notoria inseguridad sobre el curso de la civilización occidental, realmente amenazada por la crisis energética, y esto no es algo simplemente inventado por los políticos para hacer que nos despreocupemos del quehacer inmediato. El cambio que esto va a suponer, la reconversión de los sistemas industriales y urbanos, suponen rigurosas incógnitas que afectarán de lleno a la reconversión económica y social. Una planificación espacial sobre estas inciertas bases es realmente una operación aventurada, lo cual no quiere decir que tenga forzosamente que coartar cualquier iniciativa en cuanto a racionalización del uso del suelo; pero limitará las propuestas y exigirá planteamientos sobre hipótesis basadas en los futuros desarrollos sociopolíticos y socioeconómicos. 